\title{
Autoavaliação dos graduandos de Pedagogia sobre seu desempenho acadêmico no decorrer do curso
}

\author{
Sônia Aparecida Belletti Cruz ${ }^{1}$ \\ https://orcid.org/0000-0001-7138-4089 \\ Ana Flavia Moraes da Silva ${ }^{2}$ \\ https://orcid.org/0000-0003-4297-7832
}

\section{Resumo}

Sob a perspectiva piagetiana, o professor avalia não só o aluno, mas também seus saberes teóricos e práticos. Nos cursos de graduação não pode ser diferente, visto que seus currículos projetam experiências de aprendizagem que visam ao desenvolvimento do pensamento crítico e reflexivo, de capacidades para elaboração teórico-conceitual e resolução de problemas complexos e de competências coerentes às novas exigências do mundo do trabalho. Os resultados da pesquisa, obtidos pela autoavaliação de 22 universitários do curso de Pedagogia, apontam que a maioria considera ter apresentado atitude efetiva de participação e envolvimento nas aulas. Afirmam ter realizado as atividades propostas, colaborando na execução dos trabalhos em grupo, dentre outros comportamentos tidos como adequados e que contribuem para o processo de aquisição de saberes científicos e práticos. Embora haja resistência de muitos professores em adotá-la, a autoavaliação contribui para transformações na esfera pessoal e acadêmica e na preparação para a vida profissional.

Palavras-chave: Processo de aprendizagem. Avaliação do desempenho. Autoavaliação.

\begin{abstract}
From a Piagetian perspective, the teacher does not evaluate solely the student, but also his theoretical and practical knowledge. Graduate cannot be different, since their curricula design learning experiences that aim at the development of critical and reflexive exercise, capacities for theoretical-conceptual elaboration and problem-solving skills consistent to the modern workplace demands. The research was carried out by the self-evaluation of 22 university students of the Pedagogy course, pointing out that most of them considered themselves in a position to participate effectively in classes. They state to have implemented the proposed activities, collaborating for the execution of group work, besides acting as professionals and contributing to the process of acquiring scientific and practical knowledge. Although many teachers resist adopting the self-evaluation, it contributes for changes in personal and academic learning and professional life.
\end{abstract}

Keywords: Learning process, performance evaluation, self-evaluation.

Doutora em Educação Escolar pela UNESP de Araraquara-SP. Professora da rede estadual paulista e da UNIP de Araraquara-SP. E-mail: soniabelletti@yahoo.com.br.

2 Graduanda em Pedagogia pela UNIP de Araraquara. E-mail:annamooraes@hotmail.com 
Introdução

A avaliação escolar é instrumento valioso do processo de ensino e aprendizagem, apresentando-se como norte do Projeto Pedagógico de toda instituição escolar.

Antes, utilizada obsessivamente para apontar acertos e erros e atribuir nota, era utilizada pelo professor para aprovar ou reprovar seu aluno.

A partir da década de 80 do século passado novas concepções a respeito do processo de aprendizagem vêm sendo elaboradas e, consequentemente, procedimentos diversos têm sido adotados para avaliar os alunos.

Sob a perspectiva piagetiana, na qual a aprendizagem é tida como construção de conhecimento e o aluno, participante ativo de todo seu processo, aspectos importantes da avaliação integral devem ser considerados: reconhecimento dos níveis de aprendizagem; comparação entre o conhecimento anterior e atual; acompanhamento do desempenho nas atividades; valorização do processo elaborado para chegar à resposta; compreensão do erro como uma fase passageira e inevitável no processo ensino-aprendizagem; atenção aos aspectos afetivo, emocional, social e cognitivo; respeito ao ritmo para aprender; observando o caminho, as tentativas, as dúvidas e os progressos. Ainda, o permanente trabalho de ação-reflexão-ação docente, em processo de avaliar não só o aluno, mas seus saberes teóricos e práticos, bem como, a proposta da escola, no sentido de utilizar os resultados das avaliações para promover adequações, manter ou reformular os planos de trabalho.

Entretanto, a avaliação ainda acontece de forma problemática na prática pedagógica. Para o professor, o dilema está no aproveitamento escolar: sua decisão ao aprovar ou reprovar pode influenciar a vida futura do aluno, aumentar ou diminuir os índices de repetência e também os de evasão escolar.

Embora haja professores que se esforcem para elaborar avaliação condizente aos conteúdos trabalhados e que visa conhecer os avanços e dificuldades dos alunos, muitos ainda demonstram não saber avaliar. Transformam a prova em momento de cobrança de conteúdos memorizados e mal compreendidos, ou mesmo, de punição para o aluno, que se desespera ao se deparar com questões desconexas e sem significado para ele.

O modelo construtivista propõe uma nova relação entre professor, aluno e conhecimento, partindo do princípio de que o aluno não é acumulador e repetidor de informações recebidas e sim construtor do seu saber, do próprio conhecimento e o professor atua como mediador, estimulando a construção do pensamento (MORETO, 2010). Portanto, o objetivo da avaliação é favorecer a aprendizagem dos alunos e a intervenção mais acertada do professor, no que diz respeito aos procedimentos de ensino e aos instrumentos avaliativos adotados.

E, nos cursos de graduação não pode ser diferente, visto que seus currículos projetam experiências de aprendizagem que visam ao desenvolvimento do pensamento crítico e reflexivo, de capacidades para elaboração teórico-conceitual e resolução de problemas complexos e de competências coerentes às novas exigências do mundo do trabalho.

A partir de tais premissas, surgem-nos alguns questionamentos a respeito das práticas adotadas para avaliar o aproveitamento acadêmico dos graduandos. O que deve ser avaliado? Quais os instrumentos avaliativos mais acertados neste nível de ensino? Os alunos percebem a importância desse momento? Compreendem a relação entre os procedimentos avaliativos e o processo de aprendizagem? São capazes de se autoavaliar? 
Segundo Garcia (2009, p. 206), as experiências avaliativas dos universitários podem influenciar, inclusive, o modo como eles "planejam e utilizam o tempo dos estudos, atribuem prioridade e significado às diversas tarefas acadêmicas e, de modo amplo, como eles se desenvolvem academicamente".

Assim, as práticas avaliativas adotadas pelos professores no ensino superior demonstram estreita relação com os diferentes níveis de desenvolvimento dos alunos no decorrer de sua graduação e com a otimização de certas atitudes e práticas em relação à aprendizagem por eles adotadas.

Partindo de tais premissas e embasado nas concepções de Hoffman, Luckesi, Melo, e Meirieu, dentre outros, o presente trabalho apresenta as respostas dos universitários das turmas dos $6^{\circ} \mathrm{e} 7^{\circ}$ períodos do curso de Pedagogia da Universidade Paulista-Araraquara-SP ao questionário que lhes foi aplicado, o qual objetivou saber sua opinião sobre seu desempenho acadêmico no decorrer do curso.

\section{Processo de ensino-aprendizagem}

Há tempo estudiosos empenham-se em investigar como ocorre a aprendizagem. Dentre várias abordagens, a interacionista abarca as correntes piagetiana e sócio-histórica, embasada nas ideias de Vygotsky, que concebem a aprendizagem como interação do sujeito com o objeto, por intermédio do pensamento e da linguagem, em ação dinâmica com o meio.

Sob o olhar desta teoria, o sujeito constrói seus conhecimentos e essa construção depende de suas condições, física, psicológica e social, e dos estímulos do meio, físico ou social, abstraindo dele o que é do seu interesse e reconstruindo, por intermédio da reflexão, o que já tem, por força dos elementos novos que abstraiu. Para Becker (2009, p. 92), se o professor embasar sua prática pedagógica nas ideias construtivistas, ao contrário de se considerar detentor e transmissor do conhecimento e de julgar seu aluno mero receptor do conteúdo a ser estudado, ele o conceberá um sujeito cultural ativo e transformador, no que se refere às dimensões assimiladora e acomodadora. "Pela dimensão assimiladora ele produz transformações no mundo objetivo, enquanto pela dimensão acomodadora produz transformações em si mesmo, no mundo subjetivo".

Também Meirieu (2005, p.144) refere-se aos processos educacionais, ao afirmar que toda nova aprendizagem coloca o aluno em situação de desafio, mexendo "com o desejo e com a inibição, com a curiosidade e com a inquietude". Não importa o nível de ensino em que o aluno se encontre, a ressonância dos novos saberes depende das suas vivências e pode representar ameaças de instabilidade de crenças e certezas que já estavam consolidadas. No entanto, "a escola está se deixando levar pela taxa de 'resultados escolares' e não pelas finalidades a que se propõe e que a qualidade de uma instituição não pode ser medida simplesmente pela satisfação de seus usuários, mas sim, pelos valores que deseja formar em seus alunos".

Nesse sentido, alerta para que a crença na educabilidade não se transforme em ações autoritárias e extremas que tiram a razão e o sentido do ato de aprender. Deve-se cuidar para não cair nos extremos do "aprender ou morrer" ou "submeta-se ao mestre ou desapareça". Isto representa não admitir fracassos e conduzir o ensino pelo "adestramento". Reitera a importância de se trabalhar conteúdos que permitam fazer a ponte entre o que é ensinado na escola e as demandas do cotidiano. 
Para isso, segundo Meirieu (2005, apud CRUZ, 2014), o caminho didático compõe-se de diferentes metodologias para alcançar o objetivo comum de todos os alunos, qual seja o de aprender e ter acesso ao desenvolvimento de capacidades de trabalhar com eficiência e pensar com autonomia.

Assim, o trabalho bem-sucedido do professor está diretamente relacionado com sua facilidade de se organizar metodologicamente, munindo-se de materiais, recursos e dispositivos tecnológicos que lhe permitam alcançar seus objetivos junto aos alunos. Ele deve se valer de estratégias pedagógicas que favoreçam aos alunos a compreensão e a elaboração dos conceitos trabalhados em sala de aula, deve delimitar o espaço, definir os objetivos comuns, estruturar o tempo e explicitar as instruções para a realização das atividades.

São concepções que reforçam algumas ideias das Pedagogias Institucional e Diferenciada, as quais enfatizam a participação ativa dos alunos e a força do grupo para o cumprimento dos trabalhos escolares. Técnicas e métodos abertos e ativos utilizados em sala de aula estimulam situações novas e variadas que demandam ações pessoais dos sujeitos envolvidos. Propõem a resolução de problemas que vão surgindo no grupo (cognitivos, sociais e emocionais). “Aos envolvidos, é uma construção que impõe vontade, que vai além da razão e necessita da conscientização das pessoas. Requer iniciativa, ação e perseverança. Propõe o consenso, o processo de formação do indivíduo e o trabalho do sujeito a partir do que ele é e do que ele sabe” (CRUZ, 2014, p. 38).

Sob esse olhar, o professor é um informante privilegiado na sala de aula, mas não o único; atividades e agrupamentos bem planejados propiciam situações nas quais os alunos também aprendem muito uns com os outros, em nível acadêmico e social, já que é essencial que as habilidades interpessoais e sociais sejam desenvolvidas nas experiências de aprendizagem cooperativa.

Para que a vivência de sala de aula se resolva em aprendizagem é necessário que se estabeleça a estreita relação entre experiência e transformação. É necessário

[...] considerar tudo o que nos passa dentro dela e ampliar a capacidade de atenção e de escuta para o que as coisas têm a dizer. Quem se propõe a ouvir, mostra disposição para se deixar levar para direções desconhecidas, para novas experiências, para novas apropriações, para a transformação (CRUZ, 2014, p. 43).

No entanto, o saber produzido pela experiência mostra-se subjetivo e relativo, visto que as pessoas que vivenciam o mesmo acontecimento podem não produzir a mesma experiência, já que é um saber que configura a personalidade, o caráter e a sensibilidade. Por isso, para que se cumpra o projeto de educar é primordial que o professor inclua emoções em suas ações e demonstre sua indignação e inquietude frente às contradições educacionais, buscando ele também transformações.

Assim, a sala de aula deve se constituir em lugar estratégico para a aprendizagem e para o desenvolvimento de valores éticos e da legitimação das regras, a fim de possibilitar o diálogo, a participação e a responsabilidade, que pressupõem a liberdade e o juízo.

\section{Avaliação da aprendizagem}

Embora as novas concepções educacionais defendam a avaliação da aprendizagem como instrumento de emancipação do aluno, no cotidiano institucional ainda prevalecem procedimentos avaliativos tradicionais, os 
quais cobram conteúdos, muitas vezes, sem significado para os alunos, que os devem memorizar para que lhes sejam atribuídas notas e, calculada sua média aritmética, a fim de definir sua aprovação ou retenção.

Talvez por se sentirem com mais poder, exercendo a função coercitiva de controle disciplinar, e mais seguros e confortáveis, já que têm total domínio na elaboração e correção das provas que demandam menos tempo, esforço e criatividade, os professores as têm adotado como instrumento corriqueiro para aferir os conhecimentos adquiridos pelos alunos, mostrando-se pouco sensibilizados em inovar.

Em tais procedimentos classificatórios, punitivos e excludentes e que compactuam com ideias autoritárias e seletivas, portanto, antidemocráticos, observa-se que o professor, no uso legal da coerção, "reduz a prática avaliativa à realização de provas obrigatórias e à atribuição de notas para fins burocráticos" (HOFFMAN, 2003, p.21).

A respeito das atitudes docentes, antes mesmo de iniciar sua formação, eles possuem sua representação de escola e de professor, pelo fato de experiências vividas como aluno, que podem ter sido boas ou ruins. No seu percurso profissional, alguns procuram imitar comportamentos que admiravam em seus mestres e evitar outros que julgavam não tão bons assim. Para Gebara e Marin (2005, p. 29), “a sua vida toda, antes e como professor, foi permeada de fatos que se relacionaram à escola, e estes fatos e experiências foram se constituindo em concepções e representações acerca do trabalho docente”. No entanto, vão mudando e ampliando suas ideias, à medida que vão amadurecendo pessoal e profissionalmente.

Segundo Melo (2012, p. 183), ainda há professores que vivenciam a avaliação "como um peso, ou como um freio, ou ainda tempo perdido, mais do que como uma ferramenta eficaz a serviço de uma pedagogia dinâmica". Desperdiçam, assim, a oportunidade de elaborar provas que realmente atendam aos objetivos das aulas e às especificidades dos conteúdos, conceitual, procedimental ou atitudinal, e verificar se estes oportunizaram aos alunos aprendizagem significativa.

Considerando que o nível de desenvolvimento do aluno reflete a eficácia do ensino, depreende-se que ao avaliar o rendimento e o avanço do aluno no processo de aprendizagem, o professor está também avaliando seu trabalho. Por isso, torna-se necessário buscar novo olhar para as práticas avaliativas e aos instrumentos adotados, elaborando-os sob a perspectiva mediadora para que propiciem aos alunos possiblidades de questionamentos, conscientização, reflexão e tomada de decisão frente às situações e aos desafios que se apresentam cotidianamente.

Visto que o ato de avaliar não se constitui atividade neutra e acidental e sim encontra-se embasado pedagógico e epistemologicamente, na concepção socioconstrutivista, para que assuma o papel de mediador entre o objeto a conhecer e o sujeito que constrói suas representações, o professor, ao contrário de ser mero transmissor de conhecimento e juiz que atribui nota, tem a função de proporcionar aos alunos experiências de aprendizagens significativas e elaborar instrumentos de avaliação também mediadores, em processo de interatividade, diálogo, confrontos de ideias e construção de saberes.

Neste contexto, o aluno toma consciência dos seus processos mentais, já que é instigado a perguntar, a comparar, a discordar e a justificar seu posicionamento, a enfrentar desafios e não ter receio de errar, compreendendo que acerto e erro fazem parte das descobertas e aprendizagens. Assim, também a avaliação toma novo sentido, que não o de apenas cumprir exigências burocráticas, mas adquire a importância de "dinamizar oportunidades de reflexão e exige um acompanhamento permanente do professor, propondo sempre ao aluno novas questões, novos 
desafios" (MELO, 2012, p. 187), podendo ele próprio avaliar suas dificuldades e competências, inclusive, seu empenho para aprender, no constante processo de autoavaliação.

Sob a perspectiva socioconstrutivista, a prática avaliativa abarca conteúdos significativos, almejando a transformação, a evolução social do aluno, que segundo Luckesi (2006, p. 32), “[...] deverá estar atenta aos modos de superação do autoritarismo e ao estabelecimento da autonomia do aluno, pois o novo modelo social exige a participação democrática de todos. Isto significa igualdade, fato que não se dará se não conquistar a autonomia e a reciprocidade de relações".

Quando o fundamental da avaliação deixa de ser a busca do acerto pelo acerto, tendo como objetivo último a nota para aprovação, adotar o procedimento avaliativo de acompanhamento do aluno em seus avanços e lhe oferecer orientações para que perceba o que deve corrigir em processo contínuo de construção de novos saberes, partindo do desenvolvimento real para atingir o desenvolvimento potencial, as intervenções investidas pelo professor encontram aporte na abordagem vigotskyana, denominada Zona de Desenvolvimento Proximal. Tal caminho percorrido pelo aluno, pautado por situações que demandam interação com os seus pares e com o ambiente, em ações concretas de cooperação, levam-no a atingir níveis de amadurecimento e de consolidação de capacidades que anteriormente não conseguia espontaneamente.

Portanto, o processo avaliativo deve implicar atitude dinâmica e assertiva do professor, no sentido de instigar o aluno a buscar novas estratégias de aprendizagem e a refletir sobre os conhecimentos por ele construídos, de forma a tomar consciência das possibilidades que lhe são oferecidas para sua formação.

\section{Práticas avaliativas promotoras de aprendizagem}

$\mathrm{Na}$ escola, de forma quantitativa ou qualitativa, os professores estão sempre avaliando seus alunos: o envolvimento com as atividades, as tarefas enviadas para realização fora da escola, a aprendizagem e o comportamento.

Com a redefinição de concepções e a adoção de novas orientações, os métodos qualitativos de avaliação se destacam, havendo maior preocupação docente em regular e adequar seus instrumentos às necessidades e particularidades dos alunos. Na visão das teorias cognitivas, os dados diagnosticados são fundamentais para que o professor opte pelos procedimentos de ensino mais acertados para explorar seus pontos de apoio e encontrar suas melhores entradas para os saberes.

Assim, por meio da avaliação diagnóstica, é possível identificar o que o aluno já sabe, seu nível de desenvolvimento real e, a partir dos conhecimentos prévios sobre o tema a ser trabalhado, oportunizar-lhe situações-problema para que mobilize suas estruturas mentais e elabore saberes mais complexos para solucionálas, alcançando o nível potencial de desenvolvimento. Tal nível é alcançado pela ponte estabelecida entre as aquisições escolares e a sua aplicabilidade nas vivências cotidianas. Uma das vantagens desta avaliação é a possibilidade de o professor detectar no processo de aprendizagem dificuldades, obstáculos, avanços e recursos a serem aperfeiçoados. Segundo Hernández (2000), é uma oportunidade para o professor planejar e rever o seu planejamento, objetivando o processo de ensino mais eficiente para o aluno que aprende. 
A perspectiva socioconstrutivista considera fundamental que se desenvolva a criticidade e autonomia para a descoberta e a construção de novos conhecimentos. Neste sentido, a mediação e interação tornam-se exercício salutar das relações sociais significativas entre os alunos entre si e o professor, na dinâmica de troca e cooperação.

Apoiada na ideia de Zona de Desenvolvimento Proximal, Linhares (1998, p. 48) desenvolveu em seus estudos os conceitos de Aprendizagem Mediada e Avaliação Cognitiva Mediada, as quais indicam que a aprendizagem é um evento social dinâmico, que depende de duas pessoas, uma melhor informada ou mais habilitada, possibilitando mediação na experiência do aprender, a fim de que o menos habilitado se torne progressivamente capaz. Sua aplicação consiste em utilizar estratégias de ajuda temporária e ajustável às necessidades do aluno para melhorar suas condições para a avaliação e permitir que revele seu desempenho potencial. Na mediação, o indivíduo mais habilitado, que pode ser o professor ou um colega de curso, orienta-o em suas tarefas na resolução de problema, com a intenção de facilitar o seu desempenho, atingindo, assim, níveis mais altos de funcionamento cognitivo. Como resultado, a autora conclui que a avaliação mediada pode ser um instrumento facilitador na resolução da tarefa em questão e funciona como suporte à autoestima do aluno, mostrando sua competência na construção de conteúdos significativos.

A avaliação formativa objetiva ajudar o aluno a progredir no caminho dos conhecimentos acadêmicos. Por meio dela é possível estimulá-lo em suas realizações de acordo com as metodologias mais adequadas ao seu nível de desenvolvimento. Fundamentada em objetivos claros e conteúdos significativos, compartilhados com os alunos, é focada nos processos cognitivos, de regulação e de autoavaliação. Para Hernández (2000, p. 150),

[...] sua finalidade não é controlar e qualificar os estudantes, mas sim ajudá-los a progredir no caminho do conhecimento, a partir do ensino que se ministra e das formas de trabalhos utilizadas em sala de aula". Por meio dela, o professor pode perceber quais intervenções pedagógica e afetiva são mais indicadas, possibilitando reformulações no seu trabalho didático.

Sob este olhar, e para que a aprendizagem se concretize, é indispensável que o aluno reconheça suas particularidades pessoais para aprender, no que se refere às competências e habilidades, e compreenda que o grau de esforço despendido nos estudos implicará positiva ou negativamente na qualidade da formação profissional que almeja. Tal tipo de avaliação contribui para a assunção de responsabilidades, que influenciará tanto no desempenho acadêmico, quanto na competência profissional.

Na autoavaliação o aluno aprimora mecanismos de compreensão e reflexão sobre seu desempenho acadêmico, que resulta em formação do cidadão crítico e responsável, capaz de atribuir significado aos novos saberes. Por meio de autocontrole das ações e comportamentos, lhe é propiciado o desenvolvimento de atitudes de autonomia e autocrítica, num exercício de identificar suas capacidades e dificuldades e compreender e adotar estratégias mais acertadas para corrigir desvios e otimizar ações para a efetivação da aprendizagem.

Silva (2007, p. 105) assim define a autoavaliação:

[...] instrumento concebido para possibilitar que os alunos analisem seu próprio desempenho, destacando pontos positivos e negativos, necessidades ou avanços, em busca do alcance de seus propósitos, os quais consistiriam, mais imediatamente, em uma aprendizagem significativa de determinado conhecimento, no domínio de determinadas competências e em sua consequente aprovação no processo. 
Vale salientar que, embora tal instrumento demonstre resultados interessantes, há forte resistência e desconfiança por parte de muitos docentes em relação à sua aplicação, com a justificativa de que os alunos tendem a se atribuir nota de desempenho que, na maioria das vezes, não merecem.

Silva (2007) afirma que, apesar de haver quem demonstre confusão em explicitar ideias quanto ao atendimento de suas expectativas sobre o curso, existem alunos que demonstram boa capacidade de pensar sobre si mesmo e, de forma crítica e consciente, avaliam seu desempenho nas disciplinas, com assunção de seus pontos fracos e dos êxitos alcançados.

Notadamente, a autoavaliação contribui para o desenvolvimento do sentimento de responsabilidade pessoal e coletiva, já que os alunos podem julgar seus esforços e socializar com os colegas saberes e atitudes, vivenciando junto com eles situações tanto agradáveis de sucesso, quanto de frustração, em casos de desacertos.

Quanto ao grau de empenho e de rendimento dos universitários, sabe-se que há influência de variados aspectos, tais como, a importância atribuída à carreira escolhida e o incentivo e respaldo da família; a condição de sua saúde física e psicológica para o enfrentamento de situações corriqueiras e adversas e o tempo dedicado ao estudo fora de sala de aula. Realizados para complementação e aprofundamento do tema/conteúdo desenvolvido, são considerados fator relevante e até decisivo para seu sucesso acadêmico e profissional (GONÇALVES, 2015).

Portanto, faz-se urgente romper com velhos paradigmas, recheados de opressão e autoritarismo, para promover avaliação que objetiva a tomada de consciência do aluno quanto à sua responsabilidade no processo de aquisição dos conhecimentos, tornando-se ele próprio o gestor de suas aprendizagens.

\section{Caminhos metodológicos}

O trabalho proposto é um estudo de caráter qualitativo, embasado nos moldes apresentados por Triviños (1992) e Minayo (2000). Consta da descrição e interpretação dos resultados obtidos por meio de ficha de autoavaliação do desempenho acadêmico.

Em relação à nossa opção pelo estudo descritivo, a fizermos pelo fato de buscarmos realizar uma investigação particular de uma questão e de a descrever com fidedignidade.

No que diz respeito à pesquisa qualitativa, Triviños (1992) mostra que, neste tipo de pesquisa, muitas informações colhidas não podem ser quantificadas e necessitam de uma interpretação mais ampla do que o simples dado objetivo. Nela, insere-se o campo do contexto, lugar comum entre os pesquisadores educacionais, que valorizam o espaço natural, no qual os indivíduos realizam suas ações e desenvolvem seu modo de vida.

No aspecto da liberdade de realização dos estudos na pesquisa qualitativa, o autor reafirma que os limites devem fazer parte da exigência científica de todo trabalho, no qual concerne a estrutura, consistência, originalidade e nível de objetivação, que são capazes de merecer a aprovação dos cientistas num processo intersubjetivo de apreciação.

Segundo Minayo (2000, p. 21-22) a pesquisa qualitativa "trabalha com o universo de significados, motivos, valores e atitudes, o que corresponde a um espaço mais profundo das relações, dos processos e dos fenômenos que não podem ser reduzidos à operacionalização de variáveis". O significado que os sujeitos dão às situações e à sua vida são pontos de convergência de atenção especial pelo pesquisador. 
Assim, a presente pesquisa, realizada no início do segundo semestre de 2018, apresenta a percepção dos universitários sobre seu empenho e rendimento durante o período que realizam parte de sua formação inicial.

\section{Sujeitos da pesquisa}

Dos vinte e oito universitários que frequentaram, no segundo semestre de 2018, a disciplina de Avaliação Educacional, nas turmas dos $6^{\circ}$ e $7^{\circ}$ períodos do curso de Pedagogia, vinte e dois realizaram a autoavaliação.

Conforme levantamento realizado, os sujeitos apresentam o seguinte perfil: um apenas pertence ao sexo masculino.

Em relação ao estado civil, dezessete são solteiros e oito são casados ou em situação de união estável. No que se refere à formação acadêmica, três possuem curso superior em outra área do conhecimento, três realizaram uma especialização e três estudaram uma língua estrangeira.

Em termos de trabalho, vinte estavam empregados no momento da pesquisa, sendo onze com atuação em instituição escolar, seis em escolas particulares e cinco em escolas públicas municipais.

No tocante às atividades realizadas, quando não estão na universidade, todos os universitários afirmam conversar com amigos e familiares e a maioria deles declara assistir à TV, ler livros, revistas etc., e brincar com jogos eletrônicos.

No que concerne ao tempo de estudos extraclasses, apenas um sujeito diz conseguir dedicar-se a mais de cinco horas por semana, sendo que o maior número de universitários destina entre uma a duas horas semanais para estudar.

\section{Resultados e discussão}

Os dados levantados foram organizados em duas categorias, analisados qualitativamente e discutidos com as ideias dos autores constantes em nosso aporte teórico.

A primeira categoria refere-se às respostas de 22 sujeitos que preencheram a ficha de autoavaliação do desempenho acadêmico.

Na segunda, encontra-se o registro da nota que os universitários se atribuíram, bem como, da palavra que consideram sintetizar seu sentimento ao ter atingido este nível de desenvolvimento no curso.

\section{Categoria 1: Ficha de autoavaliação}

Em relação ao desempenho acadêmico, o quadro 1 indica, em números de alunos para cada item, a percepção que manifestam quanto às suas habilidades e competências: 


\section{Quadro 1 - Autoavaliação.}

\begin{tabular}{|c|c|c|c|}
\hline & $\mathrm{N}^{\mathrm{o}}$ de & alunos & \\
\hline VALORES/ATITUDES/CAPACIDADES & Raramente & Às vezes & Sempre \\
\hline 1-Fui pontual & 3 & 6 & 13 \\
\hline 2- Fui assíduo & 0 & 16 & 6 \\
\hline 3- Estive atento & 0 & 17 & 5 \\
\hline 4- Fiz os trabalhos de casa & 2 & 6 & 14 \\
\hline 5- Fui organizado: registros, material para as aulas & 1 & 15 & 6 \\
\hline 6- Respeitei compromissos e cumpri prazos & 1 & 5 & 16 \\
\hline 7 - Demonstrei interesse pelos assuntos tratados & 1 & 10 & 11 \\
\hline 8- Colaborei, positivamente, nos trabalhos do grupo & 0 & 5 & 17 \\
\hline 9- Dei a minha opinião e respeitei a dos outros & 1 & 5 & 16 \\
\hline 10-Procurei cultivar a amizade e entreajuda & 0 & 5 & 17 \\
\hline 11-Estudei diariamente os assuntos dados nas aulas & 14 & 8 & 0 \\
\hline 12 - Fui capaz de colocar questões em diferentes situações & 2 & 11 & 9 \\
\hline 13- Tentei corrigir meus erros & 1 & 8 & 13 \\
\hline 14-Fui capaz de organizar e desenvolver meu trabalho sozinho & 1 & 9 & 12 \\
\hline 15-Participei, corretamente, nas atividades desenvolvidas & 2 & 6 & 14 \\
\hline 16-Participei nas aulas de forma adequada & 3 & 9 & 10 \\
\hline 17- Tomei a iniciativa de apresentar novas ideias/propostas & 8 & 10 & 4 \\
\hline 18- Aceitei críticas ao meu trabalho e/ou comportamento & 2 & 11 & 9 \\
\hline 19- Relacionei-me bem com os colegas & 1 & 10 & 11 \\
\hline 20- Fui correto no meu relacionamento com a professora & 0 & 3 & 19 \\
\hline 21- Respeitei as regras de funcionamento da turma/escola & 0 & 5 & 17 \\
\hline 22-Fui perseverante (não desisti perante as dificuldades) & 0 & 6 & 16 \\
\hline 23-Adquiri conhecimentos & 0 & 0 & 22 \\
\hline 24- Fui capaz de aplicar esses conhecimento nas provas & 0 & 12 & 10 \\
\hline 25- Fui capaz de relacionar os temas tratados na disciplina & 0 & 8 & 14 \\
\hline 26- Escrevo com clareza e correção & 1 & 11 & 10 \\
\hline 27-Utilizei materiais suplementares & 7 & 10 & 5 \\
\hline
\end{tabular}

\section{Categoria 2: Registro: nota e palavra}

Encontra-se aqui o registro da nota que os universitários se atribuíram e da palavra que consideram sintetizar o que sentem ao ter atingido este nível de desenvolvimento no curso.

\section{a) Nota da autoavaliação}

A autoavaliação do desempenho acadêmico foi expressa numericamente pelos sujeitos, que se atribuíram as notas 5,0, 7,0 e 8,0, distribuídas de acordo com o quadro 2 .

Quadro 2 - Síntese das notas.

\begin{tabular}{|c|c|}
\hline Nota & $\mathbf{N}^{\circ}$ de alunos \\
\hline 5,0 & 12 \\
\hline 7,0 & 08 \\
\hline 8,0 & 02 \\
\hline
\end{tabular}




\section{b) Palavra que sintetiza seu sentimento}

As palavras que os universitários consideram sintetizar o que sentem ao ter atingido este nível de desenvolvimento no curso encontram-se descritas no quadro 3:

Quadro 3 - Síntese das palavras.

\begin{tabular}{|l|l|}
\hline Palavra & $\mathbf{N}^{\mathbf{0}}$ de alunos \\
\hline Realizada & 02 \\
\hline Satisfação & 04 \\
\hline Persistência & 02 \\
\hline Sortuda & 01 \\
\hline Diferente & 01 \\
\hline Campeã & 01 \\
\hline Orgulhosa & 02 \\
\hline Evolução & 02 \\
\hline Superação & 02 \\
\hline Preocupada & 01 \\
\hline Feliz & 01 \\
\hline Decepção & 01 \\
\hline Ansiedade & 01 \\
\hline Descobrimento & 01 \\
\hline
\end{tabular}

Analisando a autoavaliação dos universitários, na qual puderam expressar sua percepção sobre si mesmos, refletindo a respeito de seu desempenho acadêmico no decorrer do curso, observa-se que a maioria considera ter apresentado atitude efetiva de participação e envolvimento nas aulas. Aponta ter realizado as atividades propostas, com interesse pelos assuntos tratados, respeitado compromissos e prazos, colaborando na execução dos trabalhos em grupo, dentre outros comportamentos tidos como adequados e que contribuem para o processo de aquisição de saberes científicos e práticos.

Entretanto, chamou a atenção o fato de apenas um sujeito dizer que se dedica aos estudos extraclasses por um período maior de cinco horas semanais e de haver quatro que admitem estudar menos de uma hora por semana, seguidos por doze que reconhecem estudar somente de uma a duas horas semanais. A esse respeito, Gonçalves (2015) ressalta que "tão importante quanto as horas passadas dentro da sala de aula são as horas dedicadas pelo aluno nas atividades extraclasse. O período de estudos que o graduando dedica para sua formação fora dos limites da universidade".

Quanto ao esforço empreendido, Melo (2012) afirma que o interesse do aluno está relacionado às questões cognitivas, já que se mostra atento e interessado na explanação do professor e busca explicações para o que foi trabalhado na aula, inclusive, realiza estudos complementares sobre o tema. Neste aspecto, a mediação docente torna-se primordial, propiciando situações interativas e de confronto de ideias e atuando como facilitador e catalisador do processo de aprendizagem.

Tal posicionamento também é defendido por Hoffmann (2003, p. 81), ao afirmar que a intervenção do professor 
[...] deve ser verdadeiramente desafiadora, nunca coercitiva (Não é assim!) ou retificadora (dando a resposta certa), mas devolvendo suas hipóteses sobre a forma de perguntas ou realizando novas tarefas no sentido de confrontar o aluno com outras respostas, diferentes e contraditórias, para levá-lo a defender o seu ponto de vista ou reformulá-lo.

Assim, após passar pela dinâmica de refletir sobre o que e como aprendeu e sobre os esforços que realizou, o aluno deve ser guiado pelo professor a elaborar recursos para modificar o que está inadequado. E para exercer a função de orientador dos processos educacionais, é necessário que tenha competência técnica e compromisso político. Competência técnica, no sentido de dominar o saber a ser transmitido e as habilidades para organizar e transmitir esse saber. Já o compromisso político consiste na conscientização das implicações sociais da sua prática e o compromisso a com formação cidadã de seus alunos (CAMPOS, 1995).

Em relação às respostas que abarcam as relações sociais estabelecidas com colegas de turma e integrantes do grupo de trabalho, também a maioria dos universitários julga manter bom relacionamento com os colegas, ao apontar cultivar a amizade, aceitar críticas, dar opinião e respeitar a dos outros, fato que evidencia capacidade de valorização das relações de troca e cooperação entre si. E, todos também, asseguram ter sido corretos no relacionamento com a professora.

Segundo Barbosa (2016, p. 116), ao expandir seus processos mentais, o aluno também amplia sua relação com o meio e com as pessoas com as quais convive, já que

\footnotetext{
As construções que são firmadas no contexto escolar advêm de práticas que envolvem as trocas entre os integrantes desta comunidade, o que muitas vezes requer de ambas as partes, um desprendimento de verdades que normalmente são consideradas absolutas. Neste caso, a cumplicidade e solidariedade são recorrentes nas ações escolares em ambiente socioconstrutivista.
}

Tais práticas de interação instigam ações dinâmicas de apreciação crítica, reflexiva e relacional, que promovem evolução dos sujeitos e resultam em desenvolvimento cognitivo, psíquico e social. Para isso, segundo Melo (2012), o professor deve elaborar instrumentos diversificados, relevantes e significativos, abrangendo todos os aspectos do desempenho do aluno. Consequentemente, o aluno passa a se sentir seguro e entusiasmado para se empenhar em suas descobertas e em novas relações de compartilhamento de saberes.

Já nos itens relativos às habilidades e competências, os universitários são unânimes em garantir que adquiriram conhecimentos e foram capazes de relacionar os temas tratados na disciplina e de aplicar esses conhecimentos nas provas. E, a maioria julga escrever com clareza e correção e tentar corrigir seus erros. O que é confirmado nas altas notas que se atribuem.

Em relação à palavra que expressa seus sentimentos, com exceção de "decepção", suas manifestações indicam satisfação quanto aos saberes adquiridos no curso de Pedagogia.

Seus apontamentos vêm confirmar o que vários estudos revelam: as posturas positivas dos alunos para com a dinâmica das aulas resultam na otimização das aprendizagens. Os universitários afirmam participar e se envolver ativamente com os temas desenvolvidos pelo professor e, consequentemente, adquiriram conhecimentos. Sua dedicação aos estudos e o cumprimento de seus compromissos em relação ao curso proporcionou-lhes condição ideal para seu sucesso no processo ensino/aprendizagem.

Assim, segundo Luckesi (2006), a prática avaliativa formativa possibilita ao próprio aluno diagnosticar a qualidade de suas aquisições, ao identificar dificuldades, obstáculos, avanços e aspectos que podem e devem ser 
modificados e aperfeiçoados. Ainda, oferece ao professor informações para que elabore intervenções pedagógicas e afetivas mais acertadas. Para que o processo de avaliação se concretize, é necessário que o professor tenha estabelecido e compartilhado claramente os objetivos a serem atingidos. Para Hernández (2000, p. 150), "sua finalidade não é controlar e qualificar os estudantes, mas sim ajudá-los a progredir no caminho do conhecimento, a partir do ensino que se ministra e das formas de trabalhos utilizadas em sala de aula".

Adespeito de estudos comprovarem que a autoavaliação constitui-se importante instrumento para o graduando refletir e se conscientizar sobre sua responsabilidade para com a formação profissional que escolheu, há docentes que não adotam tal instrumento avaliativo, argumentando que muitos alunos não atingiram maturidade acadêmica e intelectual, o que denota sua incapacidade para se atribuir nota ou conceito referente ao seu desempenho no processo de aprendizagem.

Para Silva (2007, p. 107), é notória a desconfiança dos professores

na capacidade dos alunos em realizar uma autoavaliação, mais precisamente na capacidade dos alunos em agirem de forma "justa" em seu próprio juízo, de não se atribuir uma nota ou conceito de que não fossem merecedores. Ou seja, para muitos professores os alunos tendem a atribuir ao próprio desempenho, por meio da autoavaliação, sempre uma nota elevada, longe da capacidade demonstrada durante as aulas.

No entanto, vale ressaltar a importância de o professor assumir seu papel de mediador, orientando e estimulando seus alunos para atendimento e adoção de certos critérios para se autoavaliar. Outro aspecto relevante da intervenção docente é possibilitar o exercício do compartilhamento e confronto de opiniões e experiência que fortalecem o trabalho colaborativo e a convivência com adversidades, propiciando tomada de consciência, assunção de responsabilidades e perseverança para avançar.

Certamente, tais práticas contribuem para transformações na esfera pessoal e acadêmica e na preparação para a vida profissional.

\section{Considerações finais}

Práticas tidas como mais democráticas adotam a autoavaliação com o propósito de regular as aquisições por meio do autocontrole que favorece o desenvolvimento da metacognição, já que propicia aos alunos a percepção de suas competências e dificuldades, seus acertos e erros e a possibilidade de elaborar estratégias para superar as supostas limitações. Por isso, é importante que o professor ofereça-lhes situações desafiadoras para que se tornem mais autônomos e se sintam capazes de se autoavaliar, ampliando seu nível de intervenção e de responsabilização no processo de ensino e aprendizagem.

Para que se compreendam as respostas que os universitários apresentaram deve-se ponderar que embora alguns se comprometem com a formação desde o início, outros levam mais tempo para se dar conta da necessidade de estudar seriamente. Fica claro que no processo educacional, não basta conhecer o que se aprende; é necessário saber também como se aprende, quais estratégias devem ser utilizadas para o cumprimento das tarefas e quais mudanças devem ser empreendidas quando os objetivos não foram atingidos. 
Portanto, as informações expressas em sua autoavaliação denotam postura de autonomia e reflexão, embora ainda se encontrem argumentos docentes que as refutem, que desconsideram sua fidedignidade.

No entanto, o descrédito que muitos professores impõem à autoavaliação dos alunos, e lhes provoca resistência em adotá-la em suas estratégias pedagógicas, pode estar lhes subtraindo momentos riquíssimos de ouvir (escutar de verdade) aqueles que precisam aprender a se expressar sobre seu pensar e seu fazer. Talvez, tais posicionamentos revelem a resistência também em se escutar, em ouvir a si próprio, dificuldade manifestada por todos nós, como bem mostra Rubem Alves, em seu texto “A Escutatória”.

\section{Referências}

BARBOSA, M. F. L. B. - Avaliação da aprendizagem na concepção socioconstrutivista para o ensino fundamental I. Revista Olhar Científico - Faculdades Associadas de Ariquemes - v. 02, n.1, Jan./Jul. 2016

BECKER, F. O que é construtivismo? Desenvolvimento e Aprendizagem sob o Enfoque da Psicologia II. UFRGS - PEAD. 2009.

CAMPOS, L. M. L. Distúrbios de aprendizagem: justificando a não permanência dos alunos na escola. In: GRANDE, M. A. R. L. (Org) A escola e seus alunos. Araraquara: Editora UNESP, 1995.

CRUZ, S. A. B. Formação continuada à luz de Meirieu: novos olhares, novos discursos, novas práticas. Curitiba: Appris, 2014.

GARCIA. J. Avaliação e aprendizagem na educação superior. Revista Est. Aval. Educ. São Paulo, v. 20, n. 43, maio/ago. 2009.

GEBARA, J.; MRIN, C. A. Representação do professor: um olhar construtivista. Ciência \& Cognição, vol. 06: 26-32, 2005.

GONÇALVES, M. P. G. e col. Influência do tempo de estudo no rendimento do aluno universitário. Revista Fundamentos, Piauí, v.2, n.2, 2015.

HERNÁNDEZ, F. Cultura visual, mudança educativa e projeto de trabalho. Porto Alegre: Artmed, 2000.

HOFFMANN, J. Avaliação mediadora uma prática em construção da pré-escola a universidade. Porto Alegre: Mediação,2003.

LINHARES, M. B. M. Avaliação assistida de crianças com queixa de dificuldade de aprendizagem: indicadores de eficiência e transferência de aprendizagem em situação de resolução de problema. In: ZUARDI, A. W.; MARTURANO, E. M.; FIGUEIREDO, A. C.; LOUREIRO, S. R. (Orgs) Estudos em saúde mental. Ribeirão Preto: FMRP/USP, 1998.

LUCKESI, C. C. Avaliação da aprendizagem escolar: estudos e proposições, São Paulo: Cortez, 2006. 
MEIRIEU, P. O quotidiano da escola e da sala de aula. Porto Alegre: Artmed, 2005.

MELO, E. S.; BASTOS.W. G. Avaliação escolar como processo de construção de conhecimento. Revista Est. Aval. Educ., São Paulo, v. 23, n. 52, p. 180-203, maio/ago. 2012.

MINAYO, M. C. S. O desafio do conhecimento: pesquisa qualitativa em saúde. Rio de Janeiro: Abrasco, 2000.

MORETTO, V. P. Prova: um momento privilegiado de estudo, não um acerto de contas. 9. ed. Rio de Janeiro: Lamparina, 2010.

SILVA, R. C. A auto-avaliação como instrumento de conscientização de alunos de um curso de especialização lato sensu. Olhar de professor, Ponta Grossa, 10(2): 101-115, 2007.

TRIVIÑOS, A. N. S. Introdução à pesquisa em Ciências Sociais: a pesquisa qualitativa em educação. São Paulo. Atlas. 1992.

Recebido em: 17/01/2019

Aprovado em: 30/07/2019 